\title{
Effect of SOD1 Overexpression on the 20S Proteasome during Aging
}

\author{
London Jacqueline*, Le Pécheur Marie \\ Université Paris Diderot, Sorbonne Paris Cité, Adaptive Functional Biology, UMR Centre National de la \\ Recherche Scientifique, Paris, France \\ Email: "Iondon@univ-paris-diderot.fr
}

Received 18 May 2016; accepted 27 June 2016; published 30 June 2016

Copyright (C) 2016 by authors and Scientific Research Publishing Inc.

This work is licensed under the Creative Commons Attribution International License (CC BY). http://creativecommons.org/licenses/by/4.0/

(c) (i) Open Access

\begin{abstract}
Metabolism of oxygen derivatives has been shown to be altered in Down syndrome (DS) due to the overexpression of the $\mathrm{Cu} / \mathrm{Zn}$ superoxide dismutase gene (SOD-1) on chromosome 21. Transgenic mice for the human SOD1 gene (hSOD1) exhibit some features of the syndrome. Oxidation of proteins and oxidative stress are involved in normal and pathological aging. The proteasome is an adaptative system to eliminate the modified proteins which can be deleterious. As SOD1 overexpression has been shown to be either deleterious or protective according to tissues and paradigms, we have measured in function of age the $20 \mathrm{~S}$ proteasome activities in neural tissues (cerebral hemisphere, cerebellum and cortex) and in the thymus and the heart from control and transgenic mice. Indeed, although SOD1 overexpression is very deleterious in thymus and heart, it has little effect in cerebral hemisphere and cortex depending on the proteolytic activity measured. Conversely in the cerebellum the three proteolytic activities decrease dramatically in transgenic old mice while it was not modified in control mice during aging. The results of this study suggest that some phenotypes of DS present in thymus, heart and neural tissues of $h S O D 1$ transgenic mice might be partially due to the modulation of the $20 S$ proteasome expression during aging.
\end{abstract}

\section{Keywords}

SOD1, Transgenic Mice, Proteasome, Aging, Thymus, Heart, Neural Tissues, Cerebellum

\section{Introduction}

Metabolism of oxygen derivatives has been shown to be altered in Down syndrome [1]-[5] due to the overexpression of the $\mathrm{Cu} / \mathrm{Zn}$ superoxide dismutase $S O D-1$ gene on chromosome 21 [5] [6]. Transgenic mice for the

"Corresponding author. 
human SOD1 gene (hSOD) were the first model for studying Down syndrome [7] and since then two other transgenic lines have been developed [8] [9]. hSOD1 transgenic mice exhibit some features of the syndrome such as premature thymic involution and early $\mathrm{T}$ lymphocytes development [10] [11], deficiency in spatial memory and LTP which can be restored by antioxidants [12], abnormal sleep pattern [13], abnormal neuropathic pain [14] and cardiac abnormalities [15]. SOD1 overexpression has been shown to be either deleterious or protective according to tissues tested and physiological situations studied [16] and indeed $S O D-1$ overexpression was shown to be protective against in vivo insults as glutamate and MPTP toxicity but deleterious for aging processes [17]-[20].

Protein oxidation in cells is a consequence of radical oxygen species production as they can oxidize specific amino acids in proteins that will be rapidly degraded by proteases [21]. Organisms have developed a complex and adaptative proteolytic system, the proteasome, to degrade selectively oxidized and damaged proteins [22]-[24] thus preventing their accumulation which can be deleterious in many diseases (review in: [25] [26]). The 26S proteasome consists of a 20S catalytic core and one or two regulatory complexes. The 20S core is a cylindrical unit consisting of 28 subunits, arranged as four heptameric rings whose activity is to degrade oxidized proteins in an ATP- and ubiquitin-independent manner (Adams et al., 2003) [27]. Under basal conditions, the 26S proteasome is used in an ATP- and ubiquitin-dependent manner to eliminate damaged proteins but under stress conditions, probably due to its higher resistance to degradation, the 20S proteasome becomes the major degradation machinery for damaged proteins thus preventing the pathogenicity caused by protein aggregates [28] [29]. The levels of ROS have been suggested to increase during aging and to contribute to aging associated alterations in many different tissues [30]. Modifications in the proteasome activities have been hypothesized to be involved in normal and pathological aging [29] [31] and it has been suggested that proteasome activation could be a novel anti-aging and anti-neurodegenerative strategy [32]-[34].

It is rather well known that persons with Down syndrome are at risk for aging [35] [36]. This aging concerns various systems: the dermic (skin dryness), the immune (early thymic involution), the ocular (early cataract, keratoconus), the musculoskeletal system, the neural system (Alzheimer-like neuro-anatomopathology).

As $S O D 1$ is an important scavenging factor against oxidative stress mediated by ROS and was shown to be either protective or deleterious in various paradigms, we checked if "in vivo" SOD1 overexpression modifies during aging the three "in vitro" proteolytic activities of the 20S proteasome in various neural organs (cerebral hemisphere, cerebellum and cortex) and in two other tissues affected by SOD1 overexpression (thymus and heart). We showed that the evolution during aging of the SOD1 activity was different in thymus, cerebral hemisphere, cortex and cerebellum from transgenic mice. Although the 20S proteasome content did not differ in function of age in the various tissues, the proteasome activities were completely different in the thymus or the heart compared to neural tissues for both controls and transgenic mice. SOD1 overexpression has a deleterious effect in the thymus and the heart as well as in the cerebellum but with a much less extent in the cerebral hemisphere and the cortex.

\section{Material and Methods}

\subsection{Animals}

hSOD-1 transgenicmice (KT line) have been obtained by microinjecting in FVB/N blastocysts a 11.5 genomic fragment of the human SOD-1 gene including its own promoter [37]. Homozygous hSOD-1 mice (SS) and control mice were generated from crosses between hemizygous ( $\mathrm{S}+$ ) transgenic mice. Transgenic and control mice used in the present study were from 15 days until 24 months-old depending on the tissue tested and were maintained on a $12 \mathrm{hr}: 12 \mathrm{hr}$ dark cycle, with food and water ad libitum. We used tissues of at least four animals of each type. All experiments were conducted in accordance with the ethical standards of French and European regulations (European Communities Council Directive, 86/609/EEC). All procedures with experimental animal were approved by University Animals Care Committee, according to the Guide for the Care and Use of Laboratory Animals.

\subsection{Genotyping}

The presence of transgene in the off springs (S/+ or SS) was confirmed by polymerase chain reaction using DNA extracted from the tail as previously [9]. 


\subsection{Tissues Extraction}

Mice were killed by decapitation and the various tissues were rapidly removed, frozen in liquid nitrogen ant stored at $-80^{\circ} \mathrm{C}$ prior to utilization. Tissues were immersed in ice-cold homogenization buffer ( $20 \mathrm{mM}$ Hepes, $0.1 \mathrm{mM}$ EDTA, $1 \mathrm{mM} \beta$-mercapto-ethanol, $\mathrm{pH}$ 7.8) and homogenized ( $1 \mathrm{ml}$ buffer/100mg tissue) utilizing an ultraturax. The homogenates were then centrifuged at $12,000 \mathrm{~g}$ for 20 minutes $\left(4^{\circ} \mathrm{C}\right)$. Supernatants were collected and protein concentration was determined using the Bradford reagent (Bio-Rad, Bethesda, USA) and bovine serum albumin (Sigma, St. Quentin-Fallavier, France) as the standard protein prior to measurements of SOD-1 and proteasome activities.

\subsection{Measurement of SOD Activities}

SOD activity was performed using the commercially available Superoxide Dismutase Assay Kit from R \& D systems. This method employs xanthine and xanthine oxidase to generate superoxide radicals which convert Nitro Blue Tetrazolium (NBT) into NBT-diformazan which absorbance is measured at $560 \mathrm{~nm}$. SOD activity is quantified by the degree of inhibition of this reaction.

\subsection{Proteasome Activities Measurements}

Three activities of the 20S proteasome were measured in protein extracts for the various tissues oftransgenic mice (S/+ or SS) and controls in absence or presence of the proteasome-specific inhibitor MG132 (N-Cbz-LeuLeu-Leucinal) to obtain the real proteasome activity. Chymotrypsine-like, trypsine-like and caspase-like activities were assayed with specific fluorigenic peptides LLVY-MCA (chymotrypsine-like), LSTR-MCA (trypsinelike) and LLE-NA (caspase-like) as previously described (Le Pecheur 2005). Excitation/Emission wavelengths were measured at 350/440 nm for LLVY-MCA and LSTR-MCA and at 333/410 nm for LLE-NA.

\subsection{Western Blotting for Proteasome}

Extracted proteins $(20 \mu \mathrm{g})$ were suspended in Laemmli buffer containing $0.5 \%$ mercaptoethanol and denatured at $95^{\circ} \mathrm{C}$ for $10 \mathrm{~min}$. Proteins were separated on $12 \%$ SDS-polyacrylamide gel and transferred to a Hybond nitrocellulose membrane (Amersham Life Science, USA) for $1 \mathrm{~h}$ at room temperature. Specific sites on the membrane were blocked $1 \mathrm{~h}$ at room temperature in a 5\% non-fat dry milk/0.2\% Tween20-PBS solution. After blocking, membranes were incubated with primary antibody (polyclonal rabbit anti-20S proteasome, 1:2000 or monoclonal mouse anti- $\beta$-actin, 1:2000 (Sigma, St. Quentin-Fallavier, France) overnight at $4{ }^{\circ} \mathrm{C}$ in $5 \%$ non-fat dry milk/0.2\% Tween20 in PBS. A secondary anti-mouse or rabbit horseradish peroxidase-conjugated antibody (Sigma, St. Quentin-Fallavier, France) was used followed by ECL detection (Amersham Life Sciences, USA) according to the supplier's instructions. Images of protein band intensities were obtained with the LAS-3000 imaging system (Fuji Photo Film Co., Ltd.). Densitometry analysis was performed using an image analyzer (Multi Gauge software, Fuji Photo Film Co., Ltd.) and densitometry measurements of the 20S proteasome levels were normalized to $\beta$-actin. All experiments were performed using two biological replicates for each sample and three different samples for each age. Scans analysis of western blots were performed using Multi Gauge ${ }^{\circledR}$ V2.02 software.

\subsection{Statistical Analysis}

One test ANOVA Newman-Keuls Multiple Comparison Test was calculated using Prism Graph Pad ${ }^{\circledR}$ Software; $\mathrm{p} \leq 0.05$ was assessed as significant. All data are represented as mean \pm SEM. $* * *, \infty \circ$ and \#\#\#p $\leq .001 ; * *, \infty$ and $\# \# \mathrm{p} \leq 0.01 ; *$, and $\# \mathrm{p} \leq 0.05$.

\section{Results}

\subsection{SOD-1 Activities}

\subsubsection{In Thymus}

SOD1 activity was measured for controls and S/+ mice aged 0.5, 1, 3 and 12 months. The SOD1 activity (Figure 1(a)) was increased until one month in transgenic and control mice (36 U/mg and $4 \mathrm{U} / \mathrm{mg}$ respectively) 


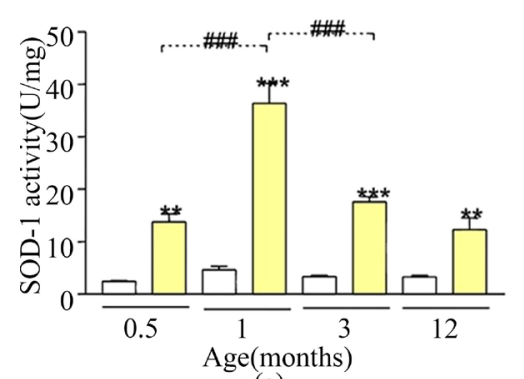

(a)

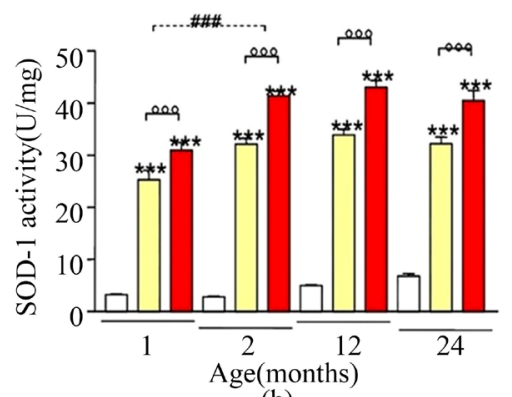

(b)

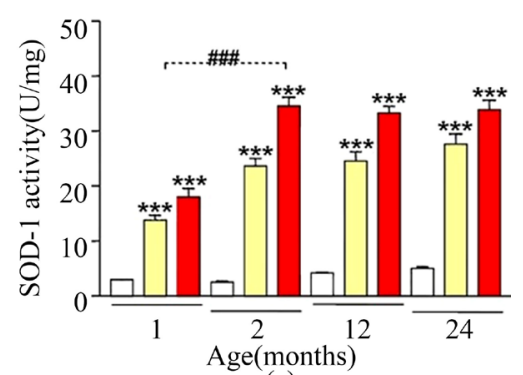

(c)

Figure 1. SOD-1 activity in thymus of $0,5,1,3,12$-months-old mice (a), in cerebral hemisphere (b) and cerebellum (c) of 1 , 2, 12 and 24-months-old mice. SOD-1 activity was assayed with the R\&D systems kit as described in materials and methods. Results are the mean of two different experiments. Results, expressed as mean \pm SEM $(n=4)$ were obtained by comparison of the values for S/+ and SS mice in yellow and red boxes respectively versus control mice in white boxes using a Student $\mathrm{t}$-test for unpaired samples and were considered significant with: ${ }^{*} \mathrm{p}<0.05$, ** $\mathrm{p}<0.01$ and $* * * \mathrm{p}<0.001$ for comparison between S/+ or SS mice and controls, ${ }^{\circ} \mathrm{p}<0.05,{ }^{\circ} \mathrm{p}<0.01$ and ${ }^{\circ 00} \mathrm{p}<0.001$ for comparison between S/+ and SS mice and $\# \mathrm{p}<0.05, \# \# \mathrm{p}<0.01$ and \# (\#\# $\mathrm{p} \leq 0.001)$ for comparison between $\mathrm{S} /+$ or SS mice in function or age.

and then decreased in the 3 and 12 month animals for both S+ and control mice (15 and $3 \mathrm{U} / \mathrm{mg}$ ). When the activities were compared between controls and $\mathrm{S}+$ tissues the overexpression was highest for the 1 month old animals ( 7 fold) and was around 3 - 4 fold for the other ages. Unfortunately we did not have access to SS samples for measurements of SOD1 activities in the thymus.

\subsubsection{In Cerebral Hemisphere}

SOD1 activity was measured in S+, SS and control animals aged 1, 2, 12 and 24 months (Figure 1(b)). In control tissues there was a small increase in SOD1 activity (2 to $5 \mathrm{U} / \mathrm{mg}$ ) for young to old animals. In the tissues from both S+ and SS animals there is a slight increase in SOD1 activity from 1 to 2 months (25 to $32 \mathrm{U} / \mathrm{mg}$ and 30 to $40 \mathrm{U} / \mathrm{mg}$ respectively), the activity being stable in older animals. The overexpression was between 6 and 9 fold in S/+ and SS animals respectively when compared to control ones. The activities in SS tissues were slightly higher than in S/+ (13\% around).

\subsubsection{In Cerebellum}

SOD1 activity was measured in S+, SS and control animals aged 1, 2, 12 and 24 months (Figure 1(c)). The SOD1 activity profile was similar to that in cerebral hemisphere for both S+ and SS and control tissues. In controls there was an increase in SOD1 activity (2 to $4 \mathrm{U} / \mathrm{mg}$ ) for young to old animals. In the tissues from both S+ and SS animals there is a slight increase in SOD1 activity from 1 to 2 months (15 to $25 \mathrm{U} / \mathrm{mg}$ and 18 to $35 \mathrm{U} / \mathrm{mg}$ respectively), the activity being stable in older animals. The overexpression was between 6 and 8 fold in $\mathrm{S} /+$ and SS animals when compared to control ones. The activities in SS tissues were slightly higher than in S/+ (12\% around).

\subsection{Proteasome Activities in Thymus, Heart, Cerebral Hemisphere, Cerebellum and Cortex}

\subsubsection{In Thymus}

The proteasome activities were measured in control and S/+ animals aged 15, 80 days and 8 months and in SS animals aged 80 days and 8 months (Figures 2(a)-(c)). In tissues for control animals, chymotrypsine- and trypsine-like activities were dramatically decreased in function of age whereas the caspase-like activity was decreased from 15 to 80 days only. In S/+ mice there was a decrease only at 8 months for chymotrypsine- and trypsine-like activities and no modification in the caspase-like activities. When the three activities for $\mathrm{S} /+$ tissues were compared to control ones at 15 days there was a decrease of $40 \%$ around whereas chymotrypsine- and caspase-like activities in tissues from S/+ and SS at 80 days and 9 months were similar. A slight decrease in the trypsine-like activity was measured in S/+ and SS tissues when compared to controls aged 8 months.

\subsubsection{In Heart}

The proteasome activities were measured in control and S/+ and SS animals aged 1, 4 and 11 months 


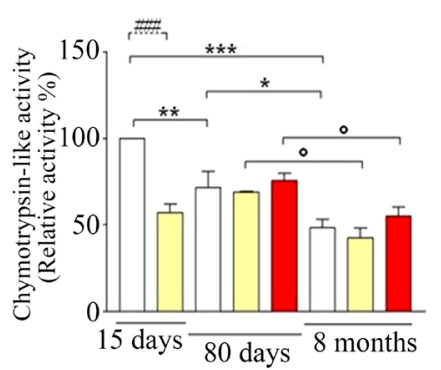

(a) Age

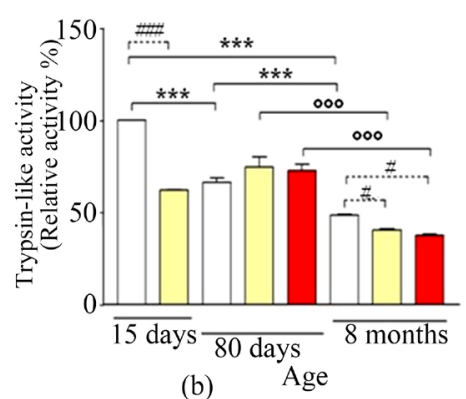

(b)

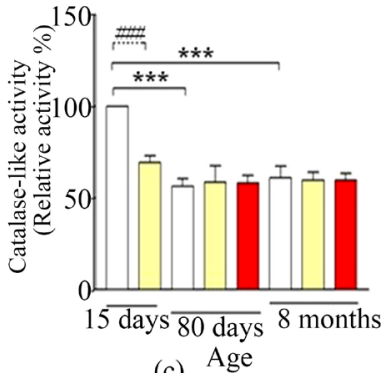

(c) Age
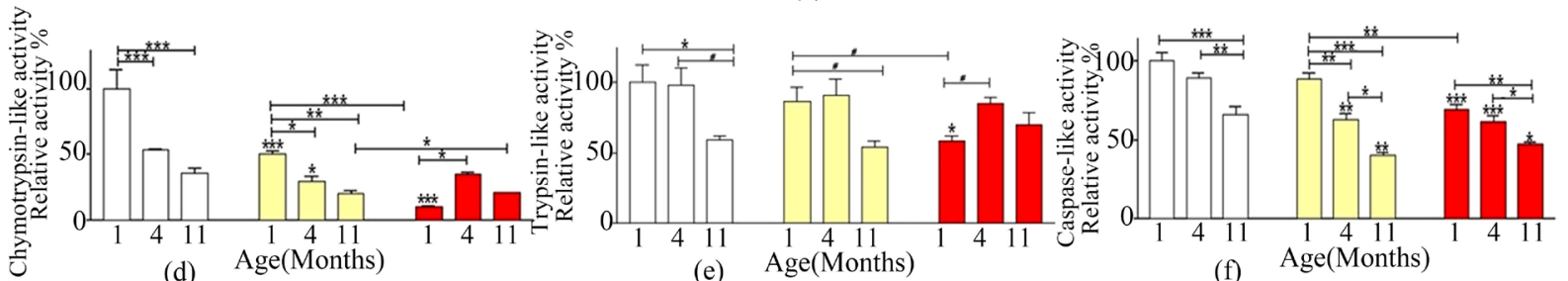

(f)

Figure 2. Proteasome activities in thymus (for 15, 80 days and 8 months-old mice) and in heart (for 1, 4, 11 months- old mice). The homogenates for chymotrypsin-((a) and (d)), trypsin-((b) and (e)) and caspase-like ((c) and (f)) activities for thymus and heart respectively were measured as described in materials and methods. Results for S/+ and SS mice are in yellow and red boxes respectively and control mice in white boxes. The results are expressed as percentage of the $100 \%$ for each proteasome activity in control mice (100\% for the 15 days thymus and $100 \%$ for the 1 month heart). In the thymus the effect of age, expressed as mean \pm SEM was obtained for each group (control, S/+ and SS) using a Student t-test for unpaired samples: ${ }^{*} \mathrm{p}<0.05$, ${ }^{* *} \mathrm{p}<0.01$ and ${ }^{* * *} \mathrm{p}<0.001$ for control mice and ${ }^{\circ} \mathrm{p}<0.05,{ }^{\circ 0} \mathrm{p}<0.01,{ }^{\circ 0} \mathrm{p}<0.001$ for $\mathrm{S} /+$ and SS mice. Comparison of the values for $\mathrm{S} /+$ and SS mice in yellow and red boxes respectively versus control mice in white boxes using a student t-test for unpaired samples is marked \#\#\# $\leq 0.001$. In the heart, all the comparisons within a group or between groups are given with the same symbols ${ }^{*} \mathrm{p}<0.05,{ }^{* *} \mathrm{p}<0.01$ and ${ }^{* * *} \mathrm{p}<0.001$ and we could not add other comparisons for technical reasons.

(Figures 2(d)-(f)). In tissues from control mice there was a decrease for the three activities in function of age which a more dramatic decrease for the chymotrypsine activity than for the two others. In control animals aged between 11 and 1 month old comparison in the three activities shows that the chymotrypsine-like activity was decreased by $60 \%$, the trypsine-like by $45 \%$ and the caspase like by $35 \%$ only. In S/+ tissues there was a dramatic decrease in the chymotrypsine-like and caspase-like activities in function of age, a decrease in trypsine-like activity was present for 11 months tissues only. But in tissues from SS animals there was a slight decrease in function of age and in the three activities. It should be pointed out that tissues from one month old animals exhibit already reduced proteasomes activities similar to those of the control ones at 11 months.

\subsubsection{In Neural Tissues}

The proteasome activities were measured in control and SS animals aged 3, 8 and 16 months in the cerebral hemisphere (Figures 3(a)-(c)), the cerebellum (Figures 3(d)-(f)) and in 7, 15 and 24 months in the cortex (Figures 3(g)-(i)). In the three tissues from control mice the proteasome activities were not modified in function of age. In the tissues from SS animals there was almost no decrease for the three activities in cerebral hemisphere and a $25 \%$ decrease for the chymotrypsin- and caspase-like activity in the cortex of 24 months mice when compared to those of 7 months. Conversely in the cerebellum there was already a slight decrease for 8 month animals when compared to 3 months and a dramatic decrease at 16 months. When SS tissues were compared to control ones there was a slight decrease (12\% around) in the three activities in the cerebral hemisphere but for 8 and 16 months tissues only. The same profile was obtained for the cerebellum but with a more drastic decrease in 16 month tissues for the three activities (30\% to 13\% according to the proteasome activities).

\subsection{Expression of the 20S Proteasome in Thymus, Cerebral Hemisphere, Cerebellum and Cortex}

To determine if the proteasome activities decrease measured in thymus and neural tissues of $h S O D-1$ transgenic 

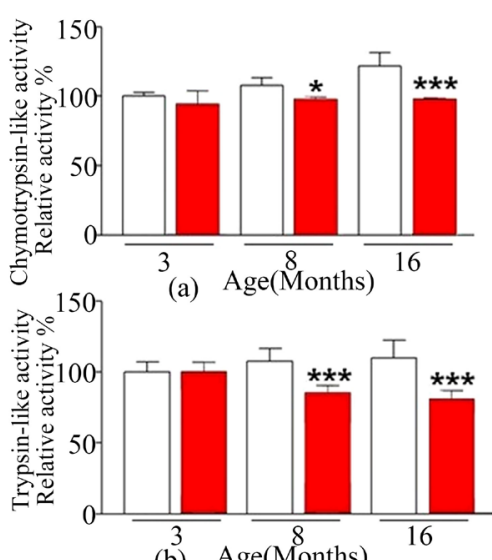

(b) Age(Months)

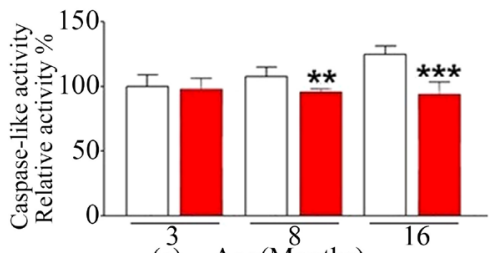

(c) Age(Months)
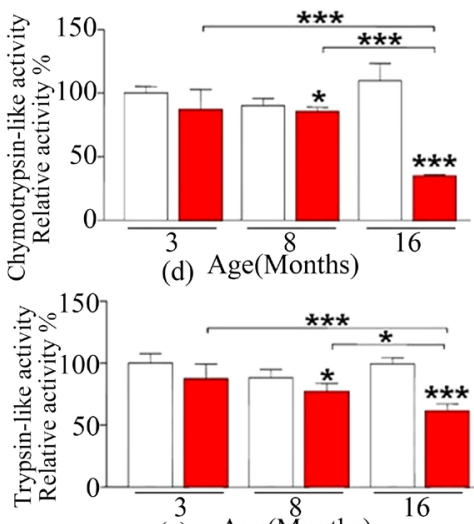

(e) Age(Months)

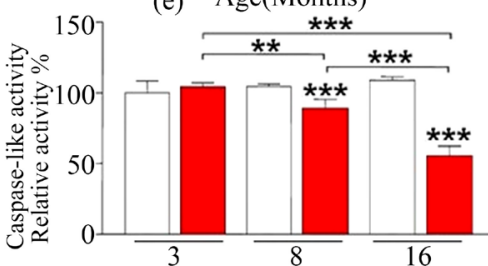

(f) Age(Months)

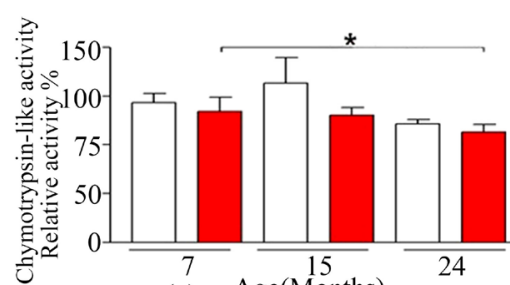

(g) Age(Months)

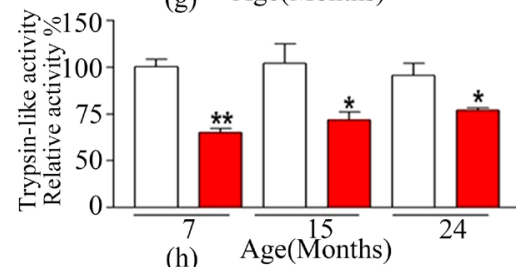

(h)

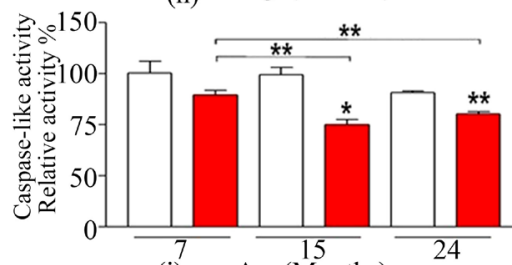

(i) Age(Months)

Figure 3. Proteasome activities in neural tissues: cerebral hemisphere and cerebellum (3, 8, 16 months-old mice), cortex (7, 15, 24 months-old mice). The homogenates of cerebral hemisphere, cerebellum are cortex are analysed for chymotrypsin((a), (d) and (g)), trypsin-((b), (e) and (h)) and caspase-like ((c), (f) and (i)) activities as described in materials and methods. The results are expressed for each proteasome activity as percentage of the $100 \%$ activity (for hemisphere and cerebellum 3-months old control mice and for the cortex 7 months old control mice). The significancy of the results, expressed as mean \pm SEM was obtained by comparison of the values for SS mice in red boxes versus control mice in white boxes using a Student t-test for unpaired samples: ${ }^{*} \mathrm{p}<0.05,{ }^{* *} \mathrm{p}<0.01$ and ${ }^{* * *} \mathrm{p}<0.001$ compared and within a group in function of age marked with the same symbols.

mice could be due to a decrease of 20S proteasome levels, we assayed by western blot analysis the amount of $20 \mathrm{~S}$ proteasome as described in material and methods. The thymus samples were from S/+, SS and control mice aged 1 months old, the cerebellum samples were from 3, 8, 16 months old SS and control mice, the cerebral hemisphere samples were from 3, 8, 16 months old SS and control mice and cortex samples were from 7 and 15 months old SS and control mice. As shown in Figure 4 there was no modification of the proteasome content in the tissues tested according to age or status (S/+, SS or control mice).

\section{Discussion}

Previous results on the same mice have shown that oxidation might explain the alteration of proteasome activities in the cortex of SOD transgenic mice [38]. Proteasome inactivation during aging is probably a general phenomenon, but is variable among selective cell types and tissues some of which being more vulnerable to age-related alterations. Thus we have measured proteasome activities in function of age in neural tissues and for comparison in two other tissues thymus and heart for which SOD1 overexpression has been shown to induce some abnormalities. We measured the proteasome activities in the thymus and the heart of both hemizygous (S/+) and homozygous (SS) transgenic mice and in the neural tissues for homozygous (SS) transgenic mice only.

As shown in the results there was in thymus a decrease in function of age for the three activities in both control and transgenic animals but in transgenic animal it was mostly in old animals and for the chymotrypsin- and trypsin-like activities only. These differences between thymus of transgenic and controls animals could be explain by the fact that there was already a decrease by $40 \%$ of the three activities in transgenic young animals. The decrease is enhanced in older transgenic animals ( 8 months) for two of three proteasome activities Thus in thymus, SOD1 overexpression, which is enhanced by a 7 fold in activity, is deleterious in very young animals but not in older ones. Besides the early thymic involution and the early $\mathrm{T}$ cell differentiation previously shown [10] [11], our present results confirm the deleterious effect of SOD1 overexpression in the thymus physiology. Interestingly, it was recently shown a decrease in the beta 5t subunit of the proteasome in the thymus of 


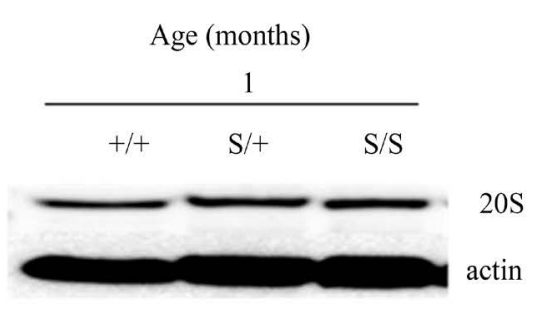

(a)

Age (months)

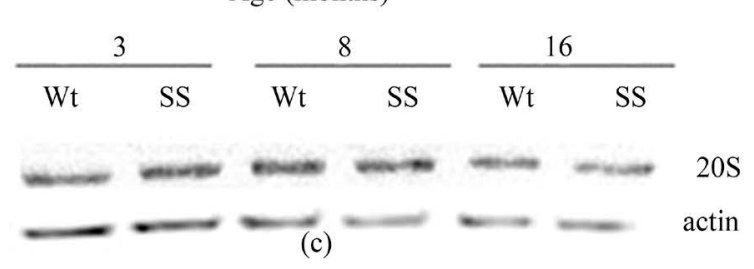

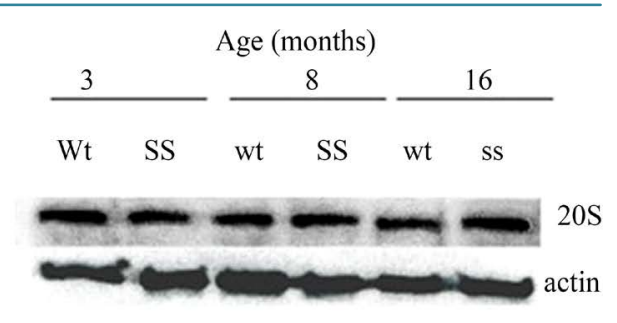

(b)

Figure 4. Western blot detection of 20S proteasome in thymus (a), cerebellum (b), cerebral hemisphere (c) and cortex (d) protein extracts. Protein extracts were prepared from SS and control mice $(+/+)$ as described in material and methods. Thymus samples (a) were from 1 month old S/+ and control mice (+/+), cerebellum (b) and cerebral hemisphere (c) samples were from 3-, 8- and 16-months old animals and cortex samples (d) from 7 and 15 months old animals. The reference protein was actin.

individuals with T21 which might explain at least partly the thymic and immunological abnormalities in these patients [39].

In the heart, previous results obtained in the rat species have shown decline in 20S proteasome activities during aging between 3 and 26 months old animals [40] [41]. In the present study using tissues of S/+, SS and controls 1 - 11 months old mice, the three proteasome activities were decreased in function of age for the three types of animals. SOD1 overexpression, induces a much earlier decrease but with a similar level as in old controls. Thus during aging the proteasome activities were decreased in heart for control and transgenic mice and SOD1 overexpression increases this deleterious effect of aging.

In the aging CNS, multicatalytic proteasome activity has been shown to be decreased in the cortex and hippocampus of very old rats but not in the cerebellum and brain stem [30]. In another study, when 15-months old rats and mice were compared with 5-months old animals [42], the chymotrypsin-like and the tryspin-like activities were decreased in the cortex and the cerebellum respectively. In the mouse (6 weeks and 15 months animals) from the same study, the chymotrypsin-like and the tryspin-like activities were decreased in the cortex and the cerebellum respectively. In the murine model to study trisomy 21, the Ts65Dn mice, chyrmotrypsin-like activity in the cerebellum was reduced by $35 \%$ [43].

In the present study we measured the three 20 proteasome activities in tissues from cerebral hemisphere and cerebellum for SS and controls 3, 8 and 16 months old animals and in the cortex 7, 15 and 24 months old animals. As shown in the results, no significant modification in function of age was shown in control mice for the three activities in the various tissues. This result can be correlated to the fact that fibroblasts from centenarians have a normal proteasome [44]. Conversely, when tissues of SS mice were compared to controls, the three proteasome activities were almost similar in the 3 months old animals and were decreased in tissues from older animals especially in the cerebellum in which the decrease was between 50 and 30\% according to the activity measured. The present result is in accordance with that obtained in the Ts65Dn mice [43]. Such decreases were also measured in the cortex but to a lesser extent. These present results can be correlated to the results of a recent study showing that in the frontal cortex of DS brain (average age 24.7 for control brains and for DS brain 23.1), the three proteasome activities were decreased [44]. Our results might also help to understand better how oxidative stress is involved in the proteostasis network involved in Down syndrome before Alzheimer pathology will be present [45]. 


\section{Conclusions}

The present study was performed to investigate if "in vivo" SOD1 overexpression induces modifications in the proteolytic activities of the 20S proteasome in various organs (thymus, heart, cerebral hemisphere, cortex and cerebellum) during aging. The results obtained show that although the SOD1 overexpression measured by the enzymatic activity is very high in most tissues tested there are significant difference among tissues during aging:

- In tissues of control mice, the SOD1 activities remain very high in neural tissues but not in thymus

- SOD overexpression induces a reduction in the proteasome activities by $20 \%-30 \%$ around in all tissues from young mice.

- During aging in control mice, the proteasome activities are almost not modified in neural tissues but are decreased dramatically in thymus and heart.

- During aging in transgenic mice, the proteasome activities decrease earlier than in controls but quantitatively no more than in the oldest control mice.

- During aging in transgenic mice, the proteasome activities decrease dramatically in heart and cerebellum.

Thus these results demonstrate that some tissues are more protected than others and it is particularly interesting that our results showed that cortex and cerebral hemisphere are protected during aging while cerebellum is not.

\section{Acknowledgements}

We thank Association Française pour la Recherchesur la trisomie 21 (AFRT) and Fondation Jérôme Lejeune for supporting the cost of this study. We thank E. Rosina and E. d'Agostino for their technical help in the experiments and E. Assayag for the manuscript figures.

\section{References}

[1] Sinet, P.M. (1982) Metabolism of Oxygen Derivatives in Down's Syndrome. Annals of the New York Academy of Sciences, 396, 83-94. http://dx.doi.org/10.1111/j.1749-6632.1982.tb26845.x

[2] Reynolds, G.P. and Cutts, A.J. (1993) Free Radical Damage in Down’s Syndrome Brain. Biochemical Society Transactions, 21, 221S. http://dx.doi.org/10.1042/bst021221s

[3] De Haan, J.B., Wolvetang, E.J., Cristiano, F., Iannello, R., Bladier, C., Kelner, M.J. and Kola, I. (1997) Reactive Oxygen Species and Their Contribution to Pathology in Down Syndrome. Advances in Pharmacology, 38, 379-402. http://dx.doi.org/10.1016/S1054-3589(08)60992-8

[4] Lott, I.T. (2012) Antioxidants in Down Syndrome. Biochimica et Biophysica Acta, 1822, 657-663. http://dx.doi.org/10.1016/j.bbadis.2011.12.010

[5] He, J., Li, T., Chen, J., Liu, Y., Xiong, F., Yang, J. and Song, C. (2016) Plasma Antioxidant Enzymes and Lipoperoxidation Status in Children with Down Syndrome. Clinical Biochemistry, 49, 61-65. http://dx.doi.org/10.1016/j.clinbiochem.2015.08.026

[6] Garlet, T.R., Parisotto, E.B., de Medeiros Gda, S., Pereira, L.C., Moreira, E.A., Dalmarco, E.M., Dalmarco, J.B. and Wilhelm Filho, D. (2013) Systemic Oxidative Stress in Children and Teenagers with Down Syndrome. Life Sciences, 93, 558-563. http://dx.doi.org/10.1016/j.lfs.2013.08.017

[7] Epstein, C.J., Avraham, K.B., Lovett, M., Smith, S., Elroy-Stein, O., Rotman, G., Bry, C. and Groner, Y. (1987) Transgenic Mice with Increased Cu/Zn-Superoxide Dismutase Activity: Animal Model of Dosage Effects in Down Syndrome. Proceedings of the National Academy of Sciences, 84, 8044-8048. http://dx.doi.org/10.1073/pnas.84.22.8044

[8] Ceballos-Picot, I., Nicole, A., Clement, M., Bourre, J.M. and Sinet, P.M. (1992) Age-Related Changes in Antioxidant Enzymes and Lipid Peroxidation in Brains of Control and Transgenic Mice Overexpressing Copper-Zinc Superoxide Dismutase. Mutation Research, 275, 281-293. http://dx.doi.org/10.1016/0921-8734(92)90032-K

[9] London, J., Paris, D., Toyama, K., Paly, E., Casanova, M. and Sinet, P.M. (1993) The Use of FVB: Ninbred Strain to Generate and Study of Transgenic Mice Expressing High Level of Cu:Zn SOD-1. Biology of the Cell, 77, 335.

[10] Nabarra, B., Casanova, M., Paris, D., Nicole, A., Toyama, K., Sinet, Ceballos, I. and London, J. (1996) Transgenic Mice Overexpressing the Human Cu/Zn-SOD Gene: Ultrastructural Studies of a Premature Thymic Involution Model of Down's Syndrome (Trisomy 21). Laboratory Investigation, 74, 617-626.

[11] Laurent, J., Paly, E., Marche, P.N. and London, J. (2006) Early Thymic T Cell Development in Young Transgenic Mice Overexpressing Human Cu/Zn Superoxide Dismutase, a Model of Down Syndrome. Free Radical Biology \& 
Medicine, 40, 1971-1980. http://dx.doi.org/10.1016/j.freeradbiomed.2006.01.029

[12] Gahtan, E., Auerbach, J.M., Groner, Y. and Segal, M. (1998) Reversible Impairment of Long-Term Potentiation in Transgenic Cu/Zn-SOD Mice. European Journal of Neuroscience, 10, 538-544. http://dx.doi.org/10.1046/j.1460-9568.1998.00058.x

[13] Colas, D., London, J., Gharib, A., Cespuglio, R. and Sarda, N. (2004) Sleep-Wake Architecture in Mouse Models for Down Syndrome. Neurobiology of Disease, 16, 291-299. http://dx.doi.org/10.1016/j.nbd.2004.03.009

[14] Kotulska, K., LePecheur, M., Marcol, W., Lewin-Kowalik, J., Larysz-Brysz, M., Paly, E., Matuszek, I. and London, J. (2006) Overexpression of Copper/Zinc-Superoxide Dismutase in Transgenic Mice Markedly Impairs Regeneration and Increases Development of Neuropathic Pain after Sciatic Nerve Injury. Journal of Neuroscience Research, 84, 10911097. http://dx.doi.org/10.1002/jnr.21000

[15] Thireau, J., Poisson, D., Zhang, B.L., Gillet, L. and Le Pécheur, M. (2008) Increased Heart Rate Variability in Mice Overexpressing the $\mathrm{Cu} / \mathrm{Zn}$ Superoxide Dismutase. Free Radical Biology \& Medicine, 45, 396-403. http://dx.doi.org/10.1016/j.freeradbiomed.2008.04.020

[16] Xing, J., Yu, Y. and Rando, T.A. (2002) The Modulation of Cellular Susceptibility to Oxidative Stress: Protective and Destructive Actions of Cu,Zn-Superoxide Dismutase. Neurobiology of Disease, 10, 234-246. http://dx.doi.org/10.1006/nbdi.2002.0504

[17] Chan, P.H., Chu, L., Chen, S.F., Carlson, E.J. and Epstein, C.J. (1990) Reduced Neurotoxicity in Transgenic Mice Overexpressing Human Copper-Zinc-Superoxide Dismutase. Stroke, 21, 80-82.

[18] Przedborski, S., Kostic, V., Jackson-Lewis, V., Naini, A.B., Simonetti, S., Fahn, S., Carlson, E., Epstein, C.J. and Cadet, J.L. (1992) Transgenic Mice with Increased Cu/Zn-Superoxide Dismutase Activity Are Resistant to N-Methyl4-Phenyl-1,2,3,6-Tetrahydropyridine-Induced Neurotoxicity. The Journal of Neuroscience, 12, 1658-1667.

[19] Busciglio, J. and Yankner, B.A. (1995). Apoptosis and Increased Generation of Reactive Oxygen Species in Down's Syndrome Neurons in Vitro. Nature, 378, 776-779. http://dx.doi.org/10.1038/378776a0

[20] Borg, J. and London, J. (2002) Copper/Zinc Superoxide Dismutase Overexpression Promotes Survival of Cortical Neurons Exposed to Neurotoxins in Vitro. Journal of Neuroscience Research, 70, 180-189. http://dx.doi.org/10.1002/jnr.10404

[21] Chevion, M., Berenshtein, E. and Stadtman, E.R. (2000) Human Studies Related to Protein Oxidation: Protein Carbonyl Content as a Marker of Damage. Free Radical Research, 33, S99-S108.

[22] Tanaka, K. (1998) Molecular Biology of the Proteasome. Biochemical and Biophysical Research Communications, 247, 537-541. http://dx.doi.org/10.1006/bbrc.1998.8617

[23] Shringarpure, R., Grune, T. and Davies, K.J. (2001) Protein Oxidation and 20S Proteasome-Dependent Proteolysis in Mammalian Cells. Cellular and Molecular Life Sciences, 58, 442-450. http://dx.doi.org/10.1007/pl00000787

[24] Höhn, A., König, J. and Grune, T. (2013) Protein Oxidation in Aging and the Removal of Oxidized Proteins. Journal of Proteomics, 92, 132-159. http://dx.doi.org/10.1016/j.jprot.2013.01.004

[25] Catalgol, B. and Grune, T. (2012) Proteasome and Neurodegenerative Diseases. Proteasome and Neurodegenerative Diseases. Progress in Molecular Biology and Translational Science, 109, 397-414. http://dx.doi.org/10.1016/B978-0-12-397863-9.00011-0

[26] Ben-Nissan, G. and Sharon, M. (2014) Regulating the 20S Proteasome Ubiquitine-Independent Degradation Pathway. Biomolecules, 4, 862-884. http://dx.doi.org/10.3390/biom4030862

[27] Adams, J. (2003) The Proteasome: Structure, Function, and Role in the Cell. Cancer Treatment Reviews, $29,3-9$. http://dx.doi.org/10.1016/S0305-7372(03)00081-1

[28] Reinheckel, T., Sitte, N., Ullrich, O., Kuckelkorn, U., Davies, K.J. and Grune, T. (1998) Comparative Resistance of the 20S and 26S Proteasome to Oxidative Stress. Biochemical Journal, 335, 637-642. http://dx.doi.org/10.1042/bj3350637

[29] Raynes, R., Pomatto, L.C.D. and Davies, K.J.A. (2016) Degradation of Oxidized Proteins by the Proteasome: Distinguishing between the 20S, 26S, and Proteolytic Pathways. Molecular Aspects of Medicine, Epub Ahead of Print.

[30] Keller, J.N., Hanni, K.B. and Markesbery, W.R. (2000) Possible Involvement of Proteasome Inhibition in Aging: Implications for Oxidative Stress. Mechanisms of Ageing and Development, 113, 61-70. http://dx.doi.org/10.1016/S0047-6374(99)00101-3

[31] Chondrogianni, N., Stratford, F.L., Trougakos, I.P., Friguet, B., Rivett, A.J. and Gonos, E.S. (2003) Central Role of the Proteasome in Senescence and Survival of Human Fibroblasts: Induction of a Senescence-Like Phenotype upon Its Inhibition and Resistance to Stress upon Its Activation. The Journal of Biological Chemistry, 278, 28026-28037. http://dx.doi.org/10.1074/jbc.M301048200

[32] Medina, D.X., Caccamo, A. and Oddo, S. (2012) Methylene Blue Reduces A $\beta$ Levels and Rescues Early Cognitive Deficit by Increasing Proteasome Activity. Brain Pathology, 21, 140-149. 
http://dx.doi.org/10.1111/j.1750-3639.2010.00430.x

[33] Chondrogianni, N., Sakellari, M., Lefaki, M., Papaevgeniou, N. and Gonos, E.S. (2014) Proteasome Activation Delays Aging in Vitro and in Vivo. Free Radical Biology \& Medicine, 71, 303-320. http://dx.doi.org/10.1016/j.freeradbiomed.2014.03.031

[34] Gonos, E. (2014) S4-3-Proteasome Activation as a Novel Anti-Aging Strategy. Free Radical Biology \& Medicine, 75, S7. http://dx.doi.org/10.1016/j.freeradbiomed.2014.10.842

[35] Head, E., Silverman, W., Patterson, D. and Lott, I.T. (2012) Aging and Down Syndrome. Current Gerontology and Geriatrics Research, 2012, Article ID: 412536. http://dx.doi.org/10.1155/2012/412536

[36] Glasson, E.J., Dye, D.E. and Bittles, A.H. (2014) The Triple Challenges Associated with Age-Related Comorbidities in Down syndrome. The Journal of Intellectual Disability Research, 58, 393-398. http://dx.doi.org/10.1111/jir.12026

[37] Paris, D., Toyama, K., Mégarbané, A., Casanova, P.M., Sinet, P.M. and London, J. (1996) Rapid Fluorescence in situ Hybridization on Interphasic Nuclei to Discriminate between Homozygous and Heterozygous Transgenic Mice. Transgenic Research, 5, 397-403. http://dx.doi.org/10.1007/BF01980204

[38] Le Pecheur, M., Bourdon, E., Paly, E., Farout, L., Friguet, B. and London, J. (2005) Oxidized SOD1 Alters Proteasome Activities in Vitro and in the Cortex of SOD1 Overexpressing Mice. FEBS Letters, 579, 3613-3618. http://dx.doi.org/10.1016/j.febslet.2005.05.048

[39] Tomaru, U., Tsuji, T., Kiuchi, S., Ishizu, A., Suzuki, A., Otsuka, N., Ito, T., Ikeda, H., Fukasawa, Y. and Kasahara, M. (2015) Decreased Expression of Thymus-Specific Proteasome Subunit $\beta 5$ t in Down Syndrome Patients. Histopathology, 67, 235-244. http://dx.doi.org/10.1111/his.12642

[40] Bulteau, A.L., Szweda, L.I. and Friguet, B. (2002) Age-Dependent Declines in Proteasome activity in the Heart. Archives of Biochemistry and Biophysics, 397, 298-304. http://dx.doi.org/10.1006/abbi.2001.2663

[41] Li, F., Zhang, L., Craddock, J., Bruce-Keller, A.J., Dasuri, K., Nguyen, A. and Keller, J.N. (2008) Aging and Dietary Restriction Effects on Ubiquitination, Sumoylation, and the Proteasome in the Heart. Mechanisms of Ageing and Development, 129, 515-521. http://dx.doi.org/10.1016/j.mad.2008.04.007

[42] Zeng, B.Y., Medhurst, A.D., Jackson, M., Rose, S. and Jenner, P. (2005) Proteasomal Activity in Brain Differs between Species and Brain Regions and Changes with Age. Mechanisms of Ageing and Development, 126, 760-766. http://dx.doi.org/10.1016/j.mad.2005.01.008

[43] Necchi, D., Lomoio, S. and Scherini, E. (2011) Dysfunction of the Ubiquitin-Proteasome System in the Cerebellum of Aging Ts65Dn Mice. Experimental Neurology, 232, 114-118. http://dx.doi.org/10.1016/j.expneurol.2011.08.009

[44] Chondrogianni, N., Petropoulos, I., Franceschi, C., Friguet, B. and Gonos, E.S. (2000) Fibroblast Cultures from Healthy Centenarians Have an Active Proteasome. Experimental Neurology, 35, 721-728. http://dx.doi.org/10.1016/s0531-5565(00)00137-6

[45] Di Domenico, F., Coccia, R., Cocciolo, A., Murphy, M.P., Cenini, G., Head, E., Butterfield, D.A., Giorgi, A., Schinina, M.E., Mancuso, C., Cini, C. and Perluigi, M. (2013) Impairment of Proteostasis Network in Down Syndrome Prior to the Development of Alzheimer's Disease Neuropathology: Redox Proteomics Analysis of Human Brain. Biochimica et Biophysica Acta, 1832, 1249-1259. http://dx.doi.org/10.1016/j.bbadis.2013.04.013

\section{Submit or recommend next manuscript to SCIRP and we will provide best service for you:}

Accepting pre-submission inquiries through Email, Facebook, Linkedin, Twitter, etc A wide selection of journals (inclusive of 9 subjects, more than 200 journals)

Providing a 24-hour high-quality service

User-friendly online submission system

Fair and swift peer-review system

Efficient typesetting and proofreading procedure

Display of the result of downloads and visits, as well as the number of cited articles

Maximum dissemination of your research work

Submit your manuscript at: http://papersubmission.scirp.org/ 